among subjects sampled in 1976 at the age of 18 years who had received Salk vaccine. The authors attributed the decline in the proportion with antibodies to the waning of immunity to poliovirus after oral vaccine.

Thus evidence from various sources suggests that a cohort of children born in the middle 1960s has proportionately fewer circulating antibodies than those who are older or younger. In our view this is associated with a decline in the vaccination rates together with the interruption of vaccine courses brought about by changes from inactivated to oral vaccine and confusion over the number of doses needed. This does not rule out a possible waning in immunity after oral vaccine but does suggest that this may not be the only cause. The existence of this cohort of children, who are not so well protected as the rest of the population and who might contract poliomyelitis if they travel abroad or come in close contact with vaccinated babies who are excreting the virus, highlights the need for a complete course of vaccine or for a booster dose to be given at or around schoolleaving age.

The description of the incidence of poliomyelitis and the development and use of vaccine was taken from the annual reports of the Local Government Board, the Ministry of Health, and the Department of Health and Social Security.

\section{References}

${ }^{1}$ Mortimer PP, Cunningham P. Sero-immunity to poliovirus in children and young women: England 1972-4. F Hyg $1975 ; 74: 283-7$.

2 Codd AA, White E. Protection against poliomyelitis. Lancet 1977;ii: 1078.

${ }^{3}$ Hill AB, Martin WJ. Poliomyelitis and the social environment. Br Med $\mathcal{Y}$ 1949 ;ii:357-8.

${ }^{4}$ Daley A, Benjamin B. An epidemiological note on the outbreak of poliomyelitis in London in 1947. Medical Officer 1948;80:171-6.

${ }^{5}$ Fallon RJ. Serological epidemiology of poliomyelitis. Distribution of immunity to poliomyelitis virus. Lancet 1956;i:65-9.

${ }^{6}$ Chamberlain RN, Simpson RN. The prevalence of illness in childhood. Tunbridge Wells: Pitman Medical in association with the Fellowship of Postgraduate Medicine, 1979.

${ }^{7}$ Davie R, Butler N, Goldstein H. From birth to seven. A report of the National Child Development Study. London: Longman, 1972.

${ }^{8}$ Lamy ME, Cornu C, Desmyter J. Poliovirus antibodies in age groups an assessment of obligatory vaccination in Belgium. In: International Association of Biological Standardization, ed. International symposium on immunisation: benefit versus risk factors Brussels 1978. Basle: S Karger, 1979:207-13. (Developments in Biological Standardization No 43.)

${ }^{9}$ Bainton D, Freeman M, Magrath DI, Sheffield F, Smith JWG. Immunity of children to diphtheria, tetanus, and poliomyelitis. $B r$ Med 71979 ;i: 854-7.

${ }^{10}$ Menser MA, Collins E, Wu SW. Childhood immunisation 1979. Disturbing statistics for metropolitan Sydney. Med F Aust 1980;ii:131-57.

(Accepted 9 November 1981)

\title{
Hypoparathyroidism and hypocalcaemia during treatment for acute leukaemia
}

\author{
D B FREEDMAN, M SHANNON, P DANDONA, H G PRENTICE, A V HOFFBRAND
}

\begin{abstract}
Nine patients with acute leukaemia developed a complex syndrome of hypocalcaemia and hypomagnesaemia during treatment. These metabolic abnormalities developed rapidly in some patients and gave rise to acute symptoms. Immunoreactive parathormone concentrations in these patients were found to be either absolutely or inappropriately low.
\end{abstract}

Hypomagnesaemia and the action of chemotherapeutic agents, especially adriamycin or cytarabine, or both may have contributed to the pathogenesis of this syndrome.

\section{Introduction}

Hypokalaemia and hyponatraemia are recognised complications of acute leukaemia, particularly during treatment. ${ }^{1}$ We recently observed that very low plasma concentrations of calcium and

\footnotetext{
Metabolic Unit, Department of Chemical Pathology, Royal Free Hospital and School of Medicine, London NW3 2QG

D B FREEDMAN, $M B$, BS, registrar

P DANDONA, DPHIL, MRCP, director of metabolic unit and senior lecturer in chemical pathology

Academic Department of Haematology, Royal Free Hospital and School of Medicine, London NW3 2QG

$M$ SHANNON, MB, CHB, senior registrar

H G PRENTICE, MRCP, MRCPATH, senior lecture

A V HOFFBRAND, DM, FRCPATH, professor
}

magnesium are also common in patients with acute leukaemia during chemotherapy. These metabolic abnormalities present considerable management problems.

\section{Patients and methods}

During a nine-month period nine patients (eight female, one male; age range 10-81 years) undergoing intensive chemotherapy and radiotherapy including bone-marrow transplantation developed profound hypocalcaemia resulting in tetany in four. Before treatment all had been normocalcaemic and normomagnesaemic and had had normal renal function. Six of the patients had acute myeloblastic leukaemia (including two with acute myelofibrosis) and three acute lymphoblastic leukaemia (two T-cell, one common).

Eight of the nine patients had been resistant to or had relapsed from previous chemotherapy and had been referred for experimental treatment. At the time of onset of hypocalcaemia all were receiving their second or subsequent course of chemotherapy. Three of the patients had undergone allogeneic bone-marrow transplantation and thus had been exposed to total body irradiation and high-dose cyclophosphamide. Seven of the patients were receiving non-absorbable antibiotics (neomycin, colistin) for gastrointestinal decontamination and oral antifungal agents. All patients also received prophylactic co-trimoxazole.

All the patients suffered from moderate to severe vomiting and diarrhoea. Nutritional state measured by weight loss $(>10 \%$ body weight) was substantial in seven patients. None of the nine patients, however, had received parenteral nutrition.

Chemotherapeutic agents common to all nine patients were an anthracycline antibiotic (doxorubicin in eight and daunorubicin in one) and cytarabine. Six patients also received thioguanine. Other agents used in some but not all were etoposide, 2'deoxycoformycin, colaspase, vindesine, mAMSA, and methotrexate.

During the study period seven patients had proved bacterial 
septicaemia, which was treated with empirical aminoglycosides, intravenous penicillins, intravenous antifungal agents, and metronidazole. They were also receiving frusemide regularly because of sodium overload secondary to some of these antibiotics. A smaller number of patients required other intravenous agents, including four patients who had received acyclovir treatment.

At the time of development of the hypocalcaemia we measured plasma concentrations of magnesium and immunoreactive parathyroid hormone (iPTH) (N-terminal assay).

\section{Results}

Plasma calcium and magnesium concentrations-All nine patients became hypocalcaemic from three to 60 days (mean 30 days) after the start of treatment (table). Renal function remained normal. Hypocalcaemia and hypomagnesaemia worsened in five of the patients, with a lowest recorded corrected plasma concentration of calcium of 1.3 $\mathrm{mmol} / \mathrm{l}(5.36 \mathrm{mg} / 100 \mathrm{ml})$ and of magnesium of $0.28 \mathrm{mmol} / 1(0.68$ $\mathrm{mg} / 100 \mathrm{ml}$ ). In two of these patients who were available for follow-up serum iPTH concentration was persistently low. Eight of the nine patients had plasma magnesium concentrations that were either reduced or at the lower limit of the normal reference range; the ninth patient had a normal plasma magnesium concentration. The two patients in the best nutritional state and who were not septicaemic had

Plasma corrected calcium, phosphate, magnesium, and immunoreactive parathyroid hormone (iPTH) concentrations in nine patients receiving treatment for acute leukaemia. (Normal ranges given in parentheses)

\begin{tabular}{|c|c|c|c|c|}
\hline $\begin{array}{l}\text { Case } \\
\text { No }\end{array}$ & $\begin{array}{c}\text { Corrected } \\
\text { calcium } \\
(2 \cdot 1-2 \cdot 6 \mathrm{mmol} / \mathrm{l})\end{array}$ & $\begin{array}{c}\text { Phosphate } \\
(0 \cdot 7-1 \cdot 25 \mathrm{mmol} / \mathrm{l})\end{array}$ & $\begin{array}{c}\text { Magnesium } \\
(0 \cdot 7-1 \cdot 0 \mathrm{mmol} / \mathrm{l})\end{array}$ & $\begin{array}{c}\text { iPTH } \\
(40-120 \mathrm{pg} / \mathrm{ml})\end{array}$ \\
\hline $\begin{array}{l}1^{*} \\
2 \\
3^{*} \\
4 \\
5^{*} \\
6 \\
7 \\
8 \\
9^{*}\end{array}$ & 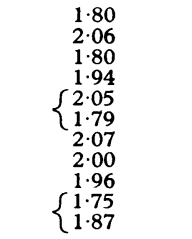 & $\begin{array}{l}1.92 \\
0.83 \\
1.48 \\
1.03 \\
1.12 \\
0.65 \\
0.83 \\
0.72 \\
1.34 \\
1.06 \\
0.86\end{array}$ & $\begin{array}{l}0.29 \\
0.71 \\
0.41 \\
0.71 \\
0.52 \\
0.40 \\
0.72 \\
0.71 \\
0.96 \\
0.39 \\
0.60\end{array}$ & $\begin{array}{r}<40 \\
<40 \\
<40 \\
52 \\
<40 \\
78 \\
55 \\
100 \\
120 \\
150 \\
<40\end{array}$ \\
\hline
\end{tabular}

*Tetany.

Conversion: SI to traditional units-Calcium: $1 \mathrm{mmol} / 1 \approx 4 \mathrm{mg} / 100 \mathrm{ml}$. Phosphate: $1 \mathrm{mmol} / 1 \approx 3 \mathrm{mg} / 100 \mathrm{ml}$. Magnesium: $1 \mathrm{mmol} / 1 \approx 2 \cdot 4 \mathrm{mg} / 100 \mathrm{ml}$.

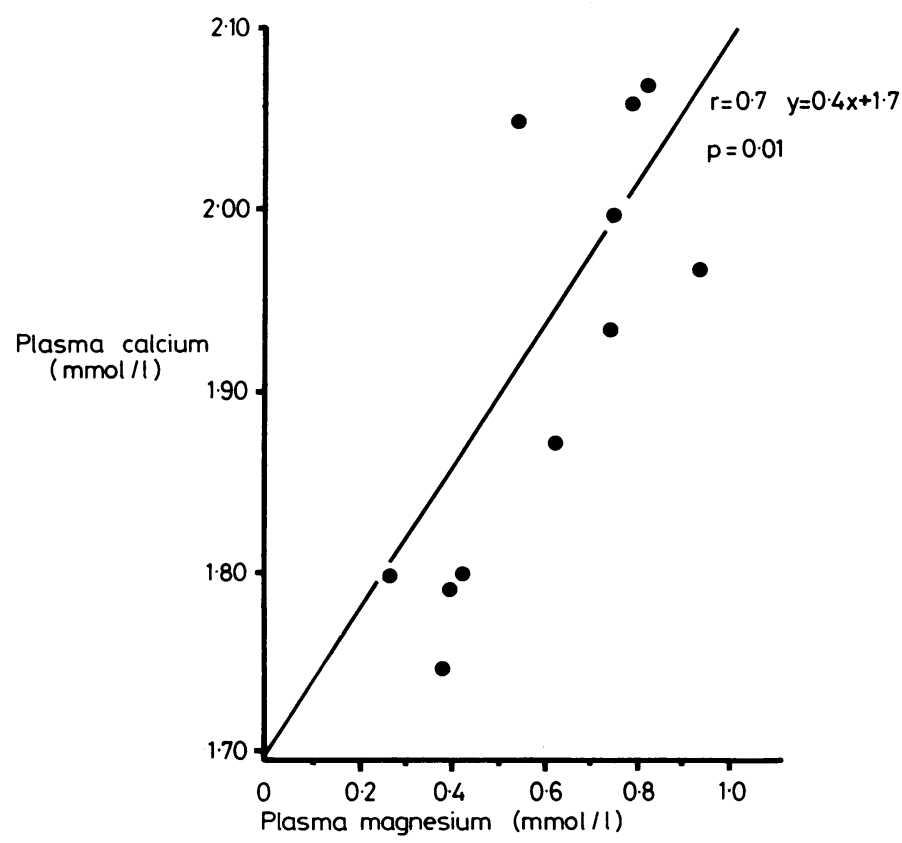

Plasma corrected calcium and magnesium concentrations in patients receiving treatment for acute leukaemia.

Conversion: SI to traditional units-Calcium: $1 \mathrm{mmol} / \mathrm{l} \approx 4 \mathrm{mg} / 100 \mathrm{ml}$. Magnesium: $1 \mathrm{mmol} / 1 \approx 2.4 \mathrm{mg} / 100 \mathrm{ml}$. the highest plasma magnesium concentrations. Their mean plasma magnesium concentration differed significantly from that in the seven other patients ( $\mathrm{p}<0.03$, Student's unpaired $t$ test). Four of the patients with the lowest plasma concentrations of calcium and magnesium developed tetany.

Plasma phosphate concentrations were raised in three patients (table). The six other patients had normal plasma phosphate concentrations, which does not exclude hypoparathyroidism as many of them were receiving intravenous dextrose, had a low dietary phosphorus intake, and were probably vitamin-D deficient. There may also have been increased renal phosphate excretion in these patients leading to hypophosphataemia, but we could not demonstrate any gross concomitant abnormality in renal function.

Parathormone concentrations-Immunoreactive parathyroid hormone (iPTH) was undetectable in the sera of four patients and was less than $120 \mathrm{pg} / \mathrm{ml}$ in a further four. The patient who had the highest iPTH concentration $(150 \mathrm{pg} / \mathrm{ml})$ in fact had a corrected plasma calcium concentration of $1.75 \mathrm{mmol} / 1(7 \mathrm{mg} / 100 \mathrm{ml})$, and a magnesium concentration that was half of the lower limit of the normal reference range: his $\mathrm{iPTH}$ concentration was thus inappropriately low for his plasma calcium concentration. These results show that $\mathrm{iPTH}$ concentration was either low in absolute terms or inappropriately low for prevalent calcium concentrations. Thus all the patients were in a state of absolute or relative hypoparathyroidism.

A significant correlation was found $(p=0.01)$ between the degree of hypocalcaemia and hypomagnesaemia (as described by Rude et $a l^{2}$ ) (figure). There was, however, no correlation between either plasma magnesium or calcium concentration and $\mathrm{PTTH}$.

\section{Discussion}

Patients in this study with hypocalcaemia and hypomagnesaemia represented about $40 \%$ of the patients who were concurrently undergoing antileukaemia treatment in this unit. All had disease that was refractory to conventional treatment and many had been referred in the terminal stages of their disease for experimental treatment, including bone-marrow transplantation. That these metabolic abnormalities are not merely a reflection of severe ill health is shown by the fact that they do not commonly occur in other illnesses and may develop fairly rapidly after the start of antileukaemic treatment. A similar syndrome has been described by Keating $e t$ al in patients with cancer receiving aminoglycoside treatment. ${ }^{3}$

A search for the mechanisms underlying these severe abnormalities suggests that malnutrition due to diarrhoea and anorexia are probably important. Diarrhoea due to total body irradiation, cytotoxic drugs, and antibiotic treatment would lead to pronounced faecal calcium and magnesium losses, as well as malabsorption of vitamin D. Furthermore, lysis of blast cells after antileukaemic treatment generates phosphate in large amounts, which would bind both calcium and magnesium. Urinary magnesium losses might also be enhanced by secondary hyperaldosteronism resulting from hypovolaemia and hypoalbuminaemia in these patients.

In addition, low plasma concentrations of magnesium would lead to inefficient conversion of adenosine triphosphate to adenosine $3^{\prime}: 5^{\prime}$-cyclic phosphate, which in turn would diminish the end organ response (including the bone and the kidney) to parathyroid hormone. ${ }^{4}$ Hypomagnesaemia is also associated with a diminished response to vitamin D. ${ }^{5}$ Finally, hypomagnesaemia would be associated with decreased ionic bone exchange of calcium for magnesium, reducing the rate of mobilisation of calcium into the plasma pool. ${ }^{6}$ ?

Another mechanism that may contribute to hypocalcaemia in these patients is the secretion of calcitonin or a similar peptide that may suppress mobilisation of calcium from the bone. $^{8}$

These patients had non-detectable, low, or only marginally raised iPTH concentrations in association with, in some cases, very low calcium concentrations: this is an unusual association. In a series of patients with osteomalacia even minimally low calcium concentrations were associated with appreciably raised iPTH concentrations (unpublished observations). Thus our patients had either absolute or "relative" hypoparathy- 
roidism, which must have contributed to the pathogenesis of hypocalcaemia. The hyposecretion of iPTH in these patients is probably secondary to several factors including hypomagnesaemia, which inhibits the secretion of iPTH both in vivo and in vitro. $^{29}$ Antimicrobial and cytotoxic drugs may also have an inhibitory effect on iPTH secretion. Vinblastine, for instance, disrupts the morphology of the parathyroid gland.10 Aminoglycosides have been incriminated in the pathogenesis of hypoparathyroidism, ${ }^{3}$ but in our series two patients developed the syndrome in the absence of aminoglycoside treatment. All nine patients, however, had been taking doxorubicin (or daunorubicin) and cytarabine; these drugs may have contributed to the suppression of parathyroid secretion.

In conclusion, we have described a syndrome that consists of a combination of hypocalcaemia, hypomagnesaemia, and a state of absolute or relative hypoparathyroidism in patients receiving treatment for acute leukaemia. In our series the syndrome was common and led to profound clinical problems, including tetany. The condition appears to be multifactorial and requires further investigation. Awareness of this metabolic problem allowed us to intervene therapeutically and to reduce morbidity. We subsequently prevented any appreciable decrease in plasma calcium and magnesium concentrations by giving appropriate supplements and $1 \alpha$-hydroxycholecalciferol. Despite this concentrations of parathyroid hormone remained low (unpublished data).

\section{References}

${ }^{1}$ Mir MA, Delamore IW. Metabolic disorders in acute myeloid leukaemia. Br F Haematol 1978;40:79-92.

${ }^{2}$ Rude RK, Oldham SB, Singer FR. Functional hypoparathyroidism and parathyroid hormone end-organ resistance in human magnesium deficiency. Clin Endocrinol (Oxf) 1976;5:209-24.

${ }^{3}$ Keating MJ, Sethi MD, Boden GP, Sa Maan NA. Hypocalcaemia with hypoparathyroidism and renal tubular dysfunction associated with aminoglycoside therapy. Cancer $1977 ; 39: 1410-4$.

${ }^{4}$ Levi J, Massry SG, Coburn JW, Llach F, Klecman CR. Hypocalcaemia in magnesium-depleted dogs; evidence for reduced responsiveness to parathyroid hormone and relative failure of parathyroid gland function. Metabolism 1974;23:324-35.

${ }^{5}$ Lifshitz F, Harrison HC, Harrison HE. Response to vitamin D of magnesium deficient rats. Proc Soc Exp Biol Med 1967;125:472-6.

${ }^{6}$ Chase CR, Slatopolsky E. Secretion and metabolic efficacy of parathyroid hormone in patients with severe hypomagnesaemia. 7 Clin Endocrinol Metab $1974 ; 38: 363-71$.

${ }^{7}$ MacManus J, Heaton FW. The influence of magnesium on calcium release from bone in vitro. Biochim Biophys Acta 1970;215:360-7.

${ }^{8}$ Hillyard CJ, Oscier DG, Foa R, Catovsky D, Goldman JM. Immunoreactive calcitonin in leukemia. $\mathrm{Br} \mathrm{Med} \mathcal{F} 1979 ; \mathrm{ii}: 1392-3$.

- Targovnik JH, Rodman JS, Sherwood LM. Regulation of parathyroid hormone secretion in vitro: quantitative aspects of calcium and magnesium ion control. Endocrinology $1971 ; 88$ :1477.

10 Reaven FP, Reaven GM. A quantitative ultrastructural study of microtubule content and secretory granule accumulation in parathyroid glands of phosphate and colchicine treated rats. $\mathcal{F}$ Clin Invest 1975; $56: 49$.

\title{
Therapeutic control of anticoagulant treatment
}

\author{
B MCD DUXBURY
}

\begin{abstract}
Control of anticoagulant treatment was studied in 250 patients. One hundred and fifty patients receiving longterm anticoagulant treatment (group 1) were studied for 52 weeks and the remaining 100 (group 2) for 12 weeks after discharge from hospital. The desired British corrected ratio range was $2 \cdot 5-3 \cdot 3$, and a range of 2.3-3.5 was classified as satisfactory. In group 1 a satisfactory ratio was obtained for $70 \%$ of the study period and 120 of the 150 patients were maintained within this range for over $60 \%$ of the time. In group 2 only half of the patients were maintained within the satisfactory range and for $50 \%$ of the study period or less. The time and effort expended in therapeutic control were more than most clinics could afford, and the results for group 2 were disappointing.
\end{abstract}

The standard of long-term anticoagulant treatment should be improved by continuous review of control and by "therapeutic quality control."

Chase Farm Hospital, Enfield EN2 8JL

B MCD DUXBURY, MB, FRCPATH, consultant haematologist

\section{Introduction}

In the early days of anticoagulant treatment haemorrhage was a real danger owing to the variable sensitivities of thromboplastins, and as a result most patients received insufficient treatment. In his historical review of anticoagulant treatment Loeliger ${ }^{1}$ stated that a ratio range of $2 \cdot 0-2 \cdot 5$ was recommended by the American Heart Association based on the earlier work of Allen et $a l^{2}{ }^{3}$ and Wright et $a l,{ }^{4}$ who had suggested ranges of $1 \cdot 5-3 \cdot 0$ and $2 \cdot 0-3 \cdot 0$ respectively. At the time this was considered to be adequate and safe. With the standardisation of thromboplastins by the introduction of British comparative thromboplastin by Poller" ${ }^{5}$ and the "external quality assessment scheme" " that followed, anticoagulant treatment was placed on a safer foundation.

Higher ratio ranges are now recommended, especially for patients who have had open-heart surgery. Blackburn ${ }^{8}$ recommended a British corrected ratio (BCR) of $2 \cdot 0-4 \cdot 0$ based on clinical experience, but Poller ${ }^{9}$ found that haemorrhage was rare in hospitals using British comparative thromboplastin as a reagent and suggested that a BCR of 5.0 was a safe upper limit for hospital patients with active thrombosis. Loeliger ${ }^{1}$ proposed that the optimum therapeutic range should be $3 \cdot 0-5 \cdot 0$ for inpatients and 2.5-4.5 for outpatients. For patients with artificial heart valves Boekhout-Mussert et al ${ }^{10}$ advised a higher range, equivalent to a BCR of $3 \cdot 0-5 \cdot 0 .{ }^{1}$ The range adopted for the "Dutch trial" 11 in elderly patients after myocardial infarction was $2 \cdot 7-4 \cdot 5$.

The effectiveness of attempting to achieve higher ratio ranges therefore requires confirmation. 